\section{AS CRISES E OS IMPACTOS DA MODERNIDADE NA VIDA DOS INDIVÍDUOS CONVIVENDO EM SOCIEDADE}

Paulo Eduardo Angelin ${ }^{1}$

\section{CRISES AND THE IMPACTS OF MODERN LIVING THE LIFE OF INDIVIDUALS IN SOCIETY}

\section{RESUMO}

O presente trabalho aborda a temática modernidade, destacando as crises e os processos perpassados por ela, bem como os seus impactos sobre o indivíduo e a sociedade. Para tanto, nos apoiaremos em Boaventura de Souza Santos, promovendo diálogos com pensadores autoridades sobre o tema, como Jürgen Habermans, Anthony Giddens, Zygmunt Bauman e Hannah Arendt. A discussão será feita em duas partes. Na primeira parte confrontaremos os autores que discutem sobre os processos de crise perpassados pela modernidade, apontando as deficiências, ambiguidades e o esgotamento do projeto da modernidade. Na segunda parte analisaremos as transformações ocorridas, tanto na vida quotidiana do indivíduo, quanto nas estruturas da sociedade, devido ao advento do paradigma sociocultural e político da modernidade.

Palavras-Chave: Modernidade, Crises, Pós-Modernidade.

\section{ABSTRACT}

This paper addresses the issue modernity, highlighting the crises and processes steeped by it, as well as their impacts on the individual and the society. To do so, we will support us in Boaventura de Souza Santos, promoting dialogues with thinkers authorities on the subject, as Jürgen Habermans, Anthony Giddens, Zygmunt Bauman and Hannah Arendt. The discussion will be in two parts. In the first part we will confront the authors that argue that the processes of crisis steeped by modernity, pointing out the weaknesses, ambiguities and the exhaustion of the project of modernity. In the second part we will analyze the changes occurred both in the everyday life of the individual, as in the structures of society, due to the advent of the sociocultural and political paradigm of modernity.

Keywords: Modernity, Crisis, Post-Modernity

1 - Graduado em Ciências Sociais pela Universidade Estadual Paulista (UNESP), mestrado em Ciência Sociais pela Universidade Federal de São Carlos (UFSCar), doutorado em Sociologia pela Universidade Federal de São Carlos (UFSCar), docente da Universidade Federal do Paraná - Setor Litoral - Rua Jaguariaíva, n. 512 - Matinhos/PR CEP: 83260-000. E-mail: pauloangelin@yahoo.com.br 


\section{1 - OS PROCESSOS DE CRISE DA MODERNIDADE}

Santos (1995) em "Pela Mão de Alice: o social e o político na pós-modernidade", afirma que estamos vivendo num período de transição, conhecido como pós-modernidade. Tal fato ocorre devido ao suposto esgotamento do projeto da modernidade. De acordo com o autor, o projeto da modernidade, em seu desenvolvimento, se comportou de maneira paradoxal, evidenciando suas limitações e chegando ao seu esgotamento. O projeto da modernidade atendeu excessivamente a certas expectativas e excluiu claramente outras. Promoveu grandes transformações no mundo social, repercutindo grandes transformações na vida cotidiana do indivíduo e, num plano mais amplo, na sociedade. Porém, tais transformações ocorreram de maneira descompassada, descontrolada, inseridas num processo sem controle. Por conta de suas limitações, desigualdades e ambiguidades, o projeto da modernidade chega ao seu esgotamento, o que nos leva a situação presente, definida por Boaventura como "situação de transição", e conhecida como pós-modernidade² (SANTOS, 1995).

A respectiva afirmação de crise e esgotamento se fundamenta na análise feita pelo autor acerca da estrutura do projeto da modernidade. Segundo Santos (1995), o projeto da modernidade tem como base de sustentação dois pilares fundamentais que possuem correspondência entre si: o pilar da regulação e o pilar da emancipação, sendo que cada um possui três princípios: o pilar da regulação tem como princípio o mercado, a comunidade e o Estado. Já o pilar da emancipação tem como base dos três princípios, a "racionalidade". Constituem o princípio da emancipação: a racionalidade estético-expressiva da arte e da literatura; a racionalidade moral-prática da ética e do direito; e a racionalidade cognitiva instrumental da ciência e da técnica. São os descompassos e limitações ocorridas em torno desses dois pilares que levaram o projeto a passar por processos de crise e ao seu efetivo esgotamento.
Ainda de acordo com Santos (1995), o projeto da modernidade esteve intrinsecamente ligado ao desenvolvimento do capitalismo nos países centrais. Assim, ao longo de sua análise, ele destaca três importantes períodos de desenvolvimento do capitalismo. O primeiro conhecido como "capitalismo Liberal" estendeu-se por todo o século XIX. O segundo período é nomeado por Boaventura de "Capitalismo Organizado", e inicia-se no final do século XIX, e atinge seu pleno desenvolvimento no período entre as duas guerras mundiais e nas primeiras décadas depois da $2^{\circ}$ guerra mundial. O terceiro período é nomeado pelo autor de "Capitalismo Desorganizado"; inicia-se no final da década de 60, e segue atualmente.

Santos (1995) afirma que o projeto da modernidade transcorreu pelos três períodos, mas se desenvolveu de maneira contraditória ou ambígua, haja vista que ele não conseguiu atender por completo e eqüitativamente as exigências dos pilares da regulação e da emancipação. Assim, no primeiro período, ele passou a ser visto como muito ambicioso e bastante contraditório, pois continha nele um excesso de promessas. Assim, em relação ao pilar da regulação, por exemplo, houve um desenvolvimento sem precedentes do princípio do mercado (crescimento vertiginoso da industrialização, aumento da importância das cidades comerciais, etc), uma estagnação do princípio da comunidade e um desenvolvimento contraditório, gerando um dualismo entre Estado e Sociedade Civil. Também é bastante contraditório neste período o desenvolvimento do pilar da emancipação, haja vista que as três lógicas desenvolveram segundo processos de especialização e de diferenciação funcional. Neste sentido, torna-se ambíguo o desenvolvimento das três lógicas, porque, ao mesmo tempo em que (arte/literatura), (ética/direito), (Ciência/técnica), possuem maior autonomia, esta conquista acabou, por conseguinte, dificultando a articulação entre elas.

No segundo período, por sua vez, algumas promessas foram cumpridas, até em excesso

2 - É certo enfatizar que esta é uma situação de transição para Boaventura, devido à situação de "vazio ou de crise, desencadeada pelo esgotamento do projeto da modernidade. Não necessariamente a pós-modernidade é uma situação de transição para outros autores, mas, o advento de um novo projeto que vêm substituir o projeto anterior. 
o que inviabilizou o cumprimento de todas as outras. Tanto o pilar de regulação, quanto o pilar da emancipação se desenvolveram de acordo com o processo de concentração/exclusão. Já no terceiro período, há a consciência de que muitas das promessas do projeto da modernidade não foram cumpridas e isso culmina num dano irreparável. É certo, portanto, que houve grandes transformações nos três períodos capitalistas em que o projeto da modernidade perpassou, mas tais transformações ocorreram de maneira descompassada, o que gerou uma desregulamentação no pilar da regulação e um esgotamento no pilar da emancipação. Por conta da contradição, insuficiência e esgotamento do projeto da modernidade, há, segundo Boaventura a necessidade de se pensar em descontinuidade e mudanças pragmáticas, isto é, pensar um novo projeto, pois estamos em uma situação de vazio e crise, denominada pósmodernidade (SANTOS, 1995).

A concepção de Boaventura se coloca em oposição ao pensamento de Habermas (1990), o qual afirma que o projeto da modernidade é, sim, imperfeito, mas podendo ser melhorado com soluções criadas pela própria modernidade. Isso ocorreria através de mudança na estrutura do projeto, a qual se encontra alicerçada no paradigma da razão instrumental. Para este autor, o projeto ficaria livre de limitações e afastaria a ideia de esgotamento, se se apoiasse no paradigma da razão comunicativa. Portanto, na visão de Habermas estamos numa situação de crises devido às limitações do projeto da modernidade, mas tal situação é caracterizada ainda como "modernidade", ou seja, nos encontramos ainda nela, e não numa situação de transição, conhecida como pós-modernidade, da qual falou Boaventura.

Por sua vez, Giddens (1997), um dos sociólogos mais importante da atualidade, afirma em "Modernização Reflexiva" que a modernidade é caracterizada por várias fases que envolvem, além de outros conceitos, "tradição" e "globalização" e implicam situações diferentes. Assim, por exemplo, as primeiras instituições modernas coexistiram e dependiam das tradições preexixtentes para se estabilizarem e, embora os processos de globalização já estivessem presente nesta fase, a comunidade local permanecera estabilizada (e permaneceram fortes até uma época relativamente recente) devido aos numerosos entraves do tradicionalismo. Giddens afirma que atualmente estamos na fase da "alta modernidade" ou "modernidade reflexiva", uma fase onde os processos de globalização são extremamente intensos, o que altera o equilíbrio entre tradição e modernidade. Estamos em "um mundo em que ninguém é 'forasteiro', é um mundo em que as tradições preexistentes não podem evitar o contato, não somente com outros - mas também com muitos - modos de vida alternativos" (GIDDENS, 1997, p.119). Compreendemos, portanto, que para o autor, o projeto da modernidade não é limitado e muito menos se esgotou. A modernidade é um paradigma sóciocultural complexo que ainda persiste sob o rótulo de "modernidade reflexiva" na qual a globalização é sua principal característica.

Outro autor que também se insere na discussão sobre a modernidade, mas que a analisa através de uma óptica diferente da de Habermas (1990) Giddens (1997) e de Santos (1995), éZygmunt Bauman. Ele aponta a necessidade de um novo projeto, mas não o projeto da pós-modernidade, haja vista que para ele já estamos vivendo a pós-modernidade.

Em "Modernidade e Ambivalência", Bauman (1999) aponta para uma das características fundamentais da modernidade, que é a noção de ambivalência. Assim, a modernidade se conforma segundo os termos sociedade $\mathrm{x}$ comunidade, autoridade $\mathrm{x}$ violência, poder $\mathrm{x}$ força, autonomia $\mathrm{x}$ heteronomia, tradição $\mathrm{x}$ ruptura, ordem $\mathrm{x}$ desordem, etc. A modernidade entra em crise quando surge um elemento novo, que rompe com a harmonia da ambivalência ou ambigüidade. Nota-se que a crise da modernidade identificada por Bauman não está relacionada à insuficiência ou limitação do projeto, mas à entrada de um terceiro elemento que destrói a lógica binária, o equilíbrio das forças. Portanto, o terceiro elemento é tudo aquilo que prejudica o equilíbrio de forças; o terceiro elemento reflete-se na lógica, quando a identidade se dá entre o idêntico e o não idêntico, entre o conhecido e o desconhecido, entre o eu e o outro. Esta situação onde há a aceitação do terceiro elemento é caracterizada por

Divers@ Revista Eletrônica Interdisciplinar / / _ Matinhos 
Bauman como "pós-modernidade".

A pós-modernidade rompe com a ambivalência, pois introduz o terceiro elemento, o estranho no jogo, que pode ser uma cultura, um grupo social, o terrorista, a rede de computadores que provoca desequilíbrio quando rompe com a segurança da lógica identitária binária. Assim, se a modernidade via no terceiro elemento um motivo de horror, de indecisão e de infelicidade, a pós-modernidade parece se comprazer da aliança entre o conhecido e o totalmente desconhecido. Na pós-modernidade, o estranho é o caos. A pós-modernidade se diferencia da modernidade, pois ela aceita o estranho, coisa que a modernidade jamais aceitaria. Mas a pós-modernidade aceita o terceiro elemento desde que ele permanece em seu lugar. De acordo com o autor, apenas numa sociedade que refaça sua lógica identitária, que permita ver o totalmente estranho com tolerância, que é possível exorcizar todos os medos em relação ao estranho (BAUMAN, 1999) .

Como vemos cada autor desenvolve uma abordagem diferente sobre os processos e crises da modernidade. Na visão de Habermans (1990), embora o projeto da modernidade seja incompleto, sua crise pode ser resolvida com recursos desenvolvidos pela própria modernidade. Portanto, para este autor, ainda estamos na era da modernidade. Para Santos (1997), o projeto da modernidade entrou em crise por não atender satisfatoriamente e eqüitativamente as necessidades dos pilares da regulação e da emancipação e, devido a isso, foi levado ao esgotamento, abrindo a fase de transição, denominada pós-modernidade. Para Giddens (1997), estamos numa fase conhecida como "alta modernidade" ou modernidade reflexiva, tendo a globalização como principal característica. Finalmente, para Bauman (1999), a modernidade entra em crise com a chegada de um terceiro elemento que rompe com a harmonia da ambivalência, característica fundamental da modernidade.

Até então, falamos sobre a estrutura e os processos de crise perpassados pela modernidade. Torna-se necessário pensar agora qual foi à relação estabelecida pela modernidade com os indivíduos e com a sociedade em geral. Quais foram os impactos sofridos pelos indivíduos e pela sociedade com o advento da modernidade? A modernidade rompeu totalmente com a tradição? Essas questões serão trabalhadas na próxima parte do trabalho.

\section{AS CONSEQUENNCIAS DA ORDEM SOCIAL MODERNA PARA A VIDA DO INDIVÍDUOE DASOCIEDADE}

Em "Modernização reflexiva" Giddens (1997) desenvolve uma discussão sobre a vida em uma ordem social moderna. Ao falar-se em "ordem social moderna", aparentemente entendemos que o autor está se referindo a uma sociedade que vive na era da modernidade e que deixou de lado a "Tradição". Contudo, como já vimos, a modernidade, embora até rompa com certas tradições, promovendo grandes transformações na vida quotidiana dos indivíduos e da sociedade, também foi caracterizada, principalmente no início do desenvolvimento social moderno, pela coexistência entre passado e presente, arcaico e novo, tradição e moderno. Ou seja, somos levados a pensar que a modernidade, ao produzir impactos sobre a vida quotidiana do indivíduo e da sociedade, os levando a perpassar por processos de reforma e transformação, rompeu abruptamente com a tradição. O que não é correto afirmar. Na verdade, Giddens (1997) aponta que as primeiras instituições modernas, além de depender das tradições já existentes, também passaram a criar novas tradições. Essa fase só foi superada com a emergência da "alta modernidade", ou "modernidade reflexiva", quando houve o completo abandono dos contextos locais de ação, devido ao crescente distanciamento no tempo e no espaço. A modernidade reflexiva, portanto, é caracterizada pela intensificação da globalização.

De acordo com Giddens (1997), as instituições modernas foram universalizadas pelos processos da globalização, característica fundamental da modernidade desde seu primórdio. Um exemplo foi o dramático crescimento da produção mundial, que sofreu flutuações e quedas. Por outro lado, também, as ações locais ou individuais produzem, em 
detrimento do processo de globalização, conseqüências que arrebentam com a barreira do localismo e atinge o mundo global.

Minha decisão de comprar uma determinada peça de roupa tem muitas implicações globais. Não somente afeta a sobrevivência de alguém que vive do outro lado do mundo, mas também pode contribuir para um processo de deterioração ecológica que em si tem consequiências potenciais para toda a humanidade (GIDDENS, 1997, p. 75).

Ou seja, os indivíduos, ao serem forçados a reformular suas ações cotidianas e pessoais e forjar suas autoidentidades, independente de quais sejam os locais de ação, acabam contribuindo intensamente para as influências sociais, que são globais em suas consequências e implicações. Por conta disso, Giddens aponta que a modernidade, através da experiência global, obrigou, não somente as comunidades locais que mantinham tradições singulares, mas, também, características íntimas da vida pessoal do individuo a passar por processos de reforma e transformação e se adequar ao mundo moderno e globalizado. Isto causou impacto profundo sobre a vida cotidiana do individuo e da sociedade em nível global.

Para Giddens (1997), portanto, é impossível dissociar a constituição das sociedades modernas, em sua complexidade atual, sem levar em conta as conseqüências dramáticas que a globalização ou os riscos sociais imprimem tanto ao indivíduo quanto à coletividade, contribuindo de forma decisiva para afetar os aspectos mais pessoais de nossa existência. Como nossa identidade não é uma entidade fixa, ela se encontra apática à determinadas influências externas, resultantes do processo de globalização, processo este característico da modernidade, e intensificado na "alta modernidade".

Giddens (1997) circunscreve a modernidade considerando tanto as situações locais, quanto as globais. Nesse sentido, pode-se afirmar que as pessoas que vivem hoje num mundo altamente moderno e globalizado, estão sujeitas à situações globais, como doenças crônicas, estresse, violência e divórcio, que apresentam tensões tanto para a vida cotidiana do indivíduo, quanto para o conjunto social. Também, pode-se dizer que, embora relativamente mais protegidos da atuação das forças naturais do que em tempos pré-modernos, tais indivíduos estão submetidos a outros riscos, considerando que suas refeições diárias podem estar muito mais acrescidas de ingredientes artificiais, agrotóxicos, etc, em detrimento daquelas consideradas mais tradicionais.

Podemos ainda pensar em uma autora importante quando discutimos os impactos causados pelos processos da modernidade na vida do indivíduo e da sociedade: Hannah Arendt. Arendt viveu numa sociedade (sociedade norte-americana) em uma época de intensa transformação. Pós-Segunda Guerra Mundial, a economia desenvolvendo e o índice de renda aumentando, foi possível o surgimento de uma sociedade com um novo estilo de vida, com múltiplos graus de alienação e o desenvolvimento de um individualismo extremo. Neste contexto, ela observou que os processos da modernidade estavam sendo capazes de solapar a capacidade de ação e compreensão dos seres humanos do mundo.

De acordo com Arendt (1989) em “A Condição Humana”, a razão atingiu seu grau máximo de desenvolvimento com o advento da modernidade. Contudo, a capacidade de pensar dos indivíduos foi aniquilada, pois, a razão se instrumentalizou. Assim, a capacidade de agir do indivíduo foi frustrada. Ou seja, modernidade consumou a ideia de subjetivação do mundo, possibilitando, assim, a instrumentalização da natureza e isso representou a generalização do que se designa ser o paradigma da fabricação. É o fortalecimento do homo-faber. O "homem fazedor e fabricante, cuja tarefa é violentar a natureza a fim de construir para si mesmo um lugar permanente" (ARENDT, 1989, p. 317). E o que significa isso? Que o homem passa a produzir artefatos intelectuais, explicativos para conhecer o mundo. Mas, quando isso avança a tal ponto, o homem acaba não mais se reconhecendo no mundo, e aliena-se em relação a ele.

De acordo com Arendt (1989), a tecnologia contribuiu muito para o surgimento da alienação. Mas a alienação do indivíduo em relação ao mundo foi para além disso. O homem, a partir do século XX, deixou de ser concebido como um ator político, ou como um fabricante de 
objetos duráveis para ser definido como um trabalhador que produz bens destinados ao consumo imediato, um trabalhador muito empenhado na manutenção do ciclo vital. Então, o homem deixou de ser concebido como um "homo-faber" para, no século XX, ser definido como um "animal laborans". É a vitória do "animal laborans" sobre o "homo-faber”, de acordo com a autora. Isso, para Arendt, é a verdadeira "perda do mundo". É a intensificação da alienação. Sendo assim, o mundo do homo-faber, tornou-se irrelevante ao se defrontar com a exigência premente da manutenção da vida do homem e da sociedade através da produção crescente de bens de consumo imediato e da repetitibilidade incessante do trabalho. Com isso, o mundo torna-se frágil é instável, pois as barreiras da estabilidade são constantemente destruídas, consumidas, em nome da abundância, do crescimento e do acúmulo de riqueza. Nesse processo, os ideais dos produtores do mundo (homo-faber), que consiste na permanência, na estabilidade e na durabilidade, são imolados em favor da abastamento, que é o ideal do animal laborans. E, no desenvolver desse processo, chegará o tempo em que todo o objeto do mundo estará destinado ao consumo e a aniquilação, através do consumo (ARENDT, 1989).

Portanto, Hannah Arendt, vivendo em uma sociedade competitiva, individualizada, devastadora, produtora de bens de consumo imediato, enfatiza sobre a incapacidade de reflexão e ação, bem como o alto grau de alienação dos indivíduos em relação ao mundo e aponta que isso foi um processo que atingiu toda a humanidade, por conta do desenvolvimento de uma razão instrumentalizada, instigada, principalmente, pelo advento da era moderna. Para Arendt (1989), o homem se aliena em relação ao mundo, pois, conhece-o, mas não se reconhece nele, e, devido a isso, ele está fora da condição humana.

Em suma, neste artigo dialogamos com autores que discutem acerca dos processos de crise perpassados pela modernidade, apontando as deficiências, ambiguidades e o esgotamento do projeto da modernidade. Também analisamos com Giddens (1997) e Arendt
(1989) as transformações ocorridas, tanto na vida quotidiana do indivíduo, quanto nas estruturas da sociedade, devido ao advento do paradigma sociocultural e político da modernidade.

\section{REFERENCIAS BIBLIOGRÁFICAS}

ARENDT, Hannah. A Condição Humana. Rio de Janeiro e São Paulo: Forense Universitária, 1989.

BAUMAN, Zygmunt. Modernidade e Ambivalência. Rio de Janeiro, Zahar, 1999.

GIDDENS, Anthony. Modernidade Reflexiva. São Paulo, Unesp, 1997.

HABERMAS, Jürgen. O Discurso Filosófico da Modernidade. Lisboa, Dom Quixote, 1990.

SANTOS, Boaventura de Souza. Pela Mão de Alice, o Social e o Político na PósModernidade. São Paulo, Cortez, 1995. 